\title{
They think they know but do they? Misalignment of perceptions of lifestyle modification knowledge among health professionals
}

\author{
Whadi-ah Parker ${ }^{1, *}$, Nelia P Steyn ${ }^{1}$, Naomi S Levitt ${ }^{2}$ and Carl J Lombard ${ }^{3}$ \\ ${ }^{1}$ Knowledge Systems, Human Sciences Research Council, Private Bag X9182, Cape Town 8000, South Africa: \\ ${ }^{2}$ Division of Diabetic Medicine and Endocrinology, Department of Medicine, University of Cape Town, Cape \\ Town, South Africa: ${ }^{3}$ Biostatistics Unit, South African Medical Research Council, Cape Town, South Africa
}

Submitted 24 August 2009: Accepted 16 December 2009: First published online 28 January 2010

\begin{abstract}
Objective: The present study aimed to evaluate the knowledge and practices of public-sector primary-care health professionals and final-year students regarding the role of nutrition, physical activity and smoking cessation (lifestyle modification) in the management of chronic diseases of lifestyle within the public healthcare sector.

Design: A comparative cross-sectional descriptive quantitative study was conducted in thirty primary health-care facilities and four tertiary institutions offering medical and/or nursing programmes in Cape Town in the Western Cape Metropole. Stratified random sampling, based on geographical location, was used to select the health facilities while convenience sampling was used to select students at the tertiary institutions. A validated self-administered knowledge test was used to obtain data from the health professionals.

Results: Differential lifestyle modification knowledge exists among both health professionals and students, with less than $10 \%$ achieving the desired scores of $80 \%$ or higher. The majority of health professionals seem to be promoting the theoretical concepts of lifestyle modification but experience difficulty in providing practical advice to patients. Of the health professionals evaluated, doctors appeared to have the best knowledge of lifestyle modification. Lack of time, lack of patient adherence and language barriers were given as the main barriers to providing lifestyle counselling.

Conclusions: The undergraduate curricula of medical and nursing students should include sufficient training on lifestyle modification, particularly practical advice on diet, physical activity and smoking cessation. Health professionals working at primary health-care facilities should be updated by providing lifestyle modification education as part of continuing medical education.
\end{abstract}

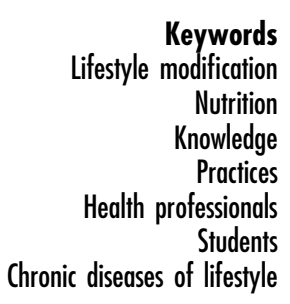

South Africa is following the global trend of urbanisation and the population is currently experiencing a nutrition transition ${ }^{(1)}$ that is being reflected in mortality patterns, as the prevalence of chronic diseases of lifestyle (CDL) has increased. IHD, stroke, chronic obstructive pulmonary disease and diabetes mellitus were among the ten leading causes of death in $2000^{(2)}$. As the public health sector serves $80 \%$ of the South African population ${ }^{(3)}$, the vast majority of people with chronic diseases and their risk factors receive their care at state-run primary health-care (PHC) facilities.

Numerous studies have shown that lifestyle modification such as adopting a healthier diet, increasing physical activity levels and smoking cessation can be effective in the prevention and management of chronic diseases, provided that the health promoters have sufficient knowledge and resources ${ }^{(4-40)}$. In South Africa, however, few trained experts in lifestyle modification such as dietitians, kinesiologists and smoking cessation counsellors are available at PHC facilities.

In actual practice, patients are most likely to have contact with health professionals such as doctors and nurses who not only are perfectly positioned to provide education and counselling on lifestyle modification, but also are viewed by patients as reliable sources of such information ${ }^{(41-48)}$. Additionally there have been numerous reports that counselling provided by these health professionals can be effective in bringing about lifestyle changes ${ }^{(49-57)}$.

Yet studies in countries such as England, Canada and the USA have demonstrated that health professionals' knowledge of lifestyle modification is not always ideal, as they may have a low level of nutrition knowledge ${ }^{(58-61)}$. Similar results were found in 2002 among general practitioners at a small number of public health facilities and 
interns at Groote Schuur Hospital in Cape Town, where only $3 \%$ of all respondents obtained a knowledge score above $75 \%$ and $31 \%$ scored less than $50 \%{ }^{(62)}$. In addition to their knowledge not being ideal, they often experience difficulty in translating the limited knowledge they do have into practical advice for patients ${ }^{(48,63)}$.

Although South Africa spends considerably more money on health care than the rest of sub-Saharan Africa $^{(64)}$, the care delivered is generally suboptimal and of variable quality, both inter- and intra-provincially as urban areas are better resourced than rural areas. Given that the Western Cape Province, in which the Cape Town Metropole district is located, is the best-resourced area in South Africa but has the highest burden of $\mathrm{CDL}^{(65,66)}$, it might be expected that health professionals in this Metropole should demonstrate substantial knowledge of CDL. The present study aimed to assess the current knowledge and practices of health professionals in the Cape Town Metropole regarding the role of lifestyle modification in the management of CDL.

\section{Methods}

\section{Study design}

A comparative multi-centre, cross-sectional, descriptive quantitative study was conducted in order to assess the knowledge and practices of both practising health professionals and final-year medical and nursing students regarding lifestyle modification in CDL.

\section{Study population}

The study was conducted in the Cape Town Metropole. This region consists of eleven districts housing forty-four health facilities that render services to CDL patients, as well as four tertiary institutions offering medical or nursing programmes. The study population included doctors, nurses and other health professionals (health promoters and nutrition advisors) who currently render services to CDL patients at public health facilities within the Cape Town Metropolitan area, as well as final-year medical and nursing students attending tertiary institutions within the Western Cape.

\section{Sample}

In order to achieve a representative sample, stratified random sampling, based on geographical location, was used to identify the health facilities that would be included in the study. Of the forty-four health facilities available, thirty facilities were selected for participation.

The sample size for the health professionals was calculated on a precision of $10 \%$ and an expected response rate of $70 \%$. In a finite population of 125 doctors and 638 nurses, a precision of $10 \%$ required a sample of sixty doctors and 110 nurses. A 30\% adjustment of the sample size was allowed for non-response, thereby increasing the required sample size to eighty-six doctors and 140 nurses. This sample would be reflective of $69 \%$ of doctors and $22 \%$ of the nurses in the study population.

All doctors present on the day of the study visit were invited to participate, including those permanently employed in PHC settings as well as doctors completing their compulsory community service year (community service doctors). Compulsory community service for medical graduates in South Africa was enforced by the Medical, Dental and Supplementary Health Service Professions Amendment Act, no. 89 of 1997. Only after completion of this one-year service are they allowed to register with the Health Professions Council of South Africa and independently practise their profession in the country.

Nurses underwent two stages of sampling - one-third of nurses practising at the facility were requested to participate in the study. The sampling was done with nurses who directly rendered services to CDL patients, nurses who were currently on CDL rotation and those present on the day the study was conducted. Three categories of nurses participated in the current study: professional or registered nurses (a graduate trained nurse who has passed a state registration examination and has been licensed to practise); enrolled nurses (carries out nursing duties under the supervision of a professional nurse); and enrolled nursing assistants (carries out nursing duties under the supervision of a professional nurse or an enrolled nurse).

A convenience sample of health promoters (health professionals who are trained in health promotion and lifestyle modification) also participated in the study at the health facilities where they were available.

In order to achieve a representative sample of students, final-year medical and nursing students at four tertiary institutions were selected to participate in the survey. These institutions included Stellenbosch University, the University of Cape Town, the University of the Western Cape and the Western Cape College of Nursing. Convenience sampling was used to include these students: all students present at a specified lecture period were included in the survey.

\section{Instruments}

A self-administered knowledge test developed and validated by Talip et al. ${ }^{(67)}$, with a Cronbach's $\alpha$ value of $0 \cdot 99$, was used in the present study. The questionnaire comprised typical local case scenarios on obesity, diabetes and hypertension. However, the demographic and practices sections of the questionnaire were adapted for applicability to the students.

A subsample of fourteen health professionals were interviewed qualitatively using a semi-structured interview schedule and a total of 580 patients were surveyed using semi-structured questionnaires. The methods and results are described in detail elsewhere ${ }^{(68)}$ but the results of these interviews are referred to in the discussion. 


\section{Etbical clearance}

Ethical clearance was obtained from the Ethics Committee at the University of Cape Town. Informed consent was provided by each participant and a memorandum containing the correct answers to the questions as well as an explanation of each answer was posted to all health facilities after completion of the study. In addition, test results were provided to students and health professionals who requested personal feedback on the test.

\section{Data analysis}

Questionnaires were checked for completion at each clinic before the researcher departed. Completed questionnaires were then coded, cleaned and computerised. Statistical analyses were conducted using the SAS statistical software package version 8 (SAS Institute, Cary, NC, USA). Regression analysis was used to determine whether actual knowledge determined participants' self-reported health practices. A cut-off point of $80 \%$ was chosen as a desired knowledge score. Scores were defined as poor (less than $40 \%$ ), mediocre (40-59\%), good (60-79\%) or excellent ( $80 \%$ or higher).

\section{Results}

A total of 318 practising health professionals were invited to participate in the study, 223 of whom completed and returned the test, resulting in an overall response rate of $70 \%$, comprising sixty-one doctors, 149 nurses and thirteen health promoters. In addition, $90 \%$ of the 199 final-year nursing students participated, as did $68 \%$ of the 327 finalyear medical students.

\section{Overall knowledge scores}

Across all groups, knowledge scores ranged from 18.5 to $88.9 \%$. Six per cent of health professionals scored poorly, $40 \%$ had mediocre scores and although $48 \%$ had good scores, only $6 \%$ achieved the desired score of $80 \%$ or higher. Similar results were achieved by students, where $5 \%, 37 \%$ and $55 \%$ had poor, mediocre and good scores, respectively, with only $3 \%$ achieving scores of $80 \%$ or higher.

\section{Actual v. perceived knowledge scores}

It is evident that the majority of health professionals overestimated their actual knowledge of lifestyle modification; $18 \%$ and $60 \%$ rated their knowledge as excellent and good, respectively, while only $6 \%$ and $48 \%$ achieved these scores, with students displaying similar results (Table 1 ).

Interestingly, doctors actually underestimated their knowledge of lifestyle modification with only $14 \%$ rating their knowledge as excellent when $20 \%$ actually achieved excellent scores. As for the medical students, 75\% achieved good scores and 5\% achieved excellent scores compared with the $57 \%$ and $17 \%$ of students who rated themselves as having good and excellent knowledge, respectively. Generally community service doctors' ratings were on par with their actual scores.

On the contrary, a much larger proportion of nurses and nursing students achieved poor scores compared

Table 1 Actual $v$. perceived knowledge scores of respondents: public-sector primary-care health professionals and final-year students participating in the survey, Cape Town, South Africa

\begin{tabular}{|c|c|c|c|c|c|}
\hline \multirow[b]{2}{*}{ Group (n) } & \multirow[b]{2}{*}{ Score } & \multicolumn{4}{|c|}{ Percentage of participants (\%) } \\
\hline & & Poor $(<40 \%)$ & Mediocre (40-59\%) & Good (60-79\%) & Excellent (80-100\%) \\
\hline \multirow[t]{2}{*}{ Health professionals (223) } & Actual & 6 & 40 & 48 & 6 \\
\hline & Perceived & 5 & 18 & 60 & 18 \\
\hline \multirow[t]{2}{*}{ Students (360) } & Actual & 5 & 37 & 55 & 3 \\
\hline & Perceived & 3 & 20 & 57 & 20 \\
\hline \multirow[t]{2}{*}{ Doctors (49) } & Actual & 0 & 18 & 61 & 20 \\
\hline & Perceived & 3 & 22 & 60 & 14 \\
\hline \multirow[t]{2}{*}{ Community service doctors (12) } & Actual & 0 & 17 & 75 & 8 \\
\hline & Perceived & 3 & 14 & 72 & 11 \\
\hline \multirow[t]{2}{*}{ Medical students (181) } & Actual & 1 & 19 & 75 & 5 \\
\hline & Perceived & 3 & 24 & 57 & 17 \\
\hline \multirow[t]{2}{*}{ Professional nurses (81) } & Actual & 4 & 42 & 54 & 0 \\
\hline & Perceived & 2 & 17 & 61 & 20 \\
\hline \multirow[t]{2}{*}{ Enrolled nurses (30) } & Actual & 10 & 60 & 30 & 0 \\
\hline & Perceived & 4 & 18 & 59 & 19 \\
\hline \multirow[t]{2}{*}{ Nursing assistants (38) } & Actual & 18 & 58 & 24 & 0 \\
\hline & Perceived & 8 & 12 & 62 & 18 \\
\hline \multirow[t]{2}{*}{ Nursing students (179) } & Actual & $9 \cdot 4$ & 54 & 36 & 0.6 \\
\hline & Perceived & 3 & 15 & 58 & 24 \\
\hline \multirow[t]{2}{*}{ Health promoters (13) } & Actual & 8 & 23 & 54 & 15 \\
\hline & Perceived & 20 & 17 & 31 & 32 \\
\hline
\end{tabular}

Professional nurse: a graduate trained nurse who has passed a state registration examination and has been licensed to practise.

Enrolled nurse: carries out nursing duties under the supervision of a professional nurse.

Nursing assistant: carries out nursing duties under the supervision of a professional nurse or an enrolled nurse.

Health promoters: health professionals specialising in health promotion and lifestyle modification. 
with their perceived ratings. Approximately $20 \%$ of nurses in each category rated their knowledge of lifestyle modification as excellent, yet none achieved scores greater than $80 \%$. Other than professional nurses, the majority of nurses achieved mediocre scores. Similar results were reported for nursing students. Although $24 \%$ of nursing students perceived their knowledge base for lifestyle modification to be excellent, less than $1 \%$ of these students achieved scores greater than $80 \%$. Furthermore, $58 \%$ of nursing students rated their knowledge as good, yet only 36\% achieved good scores. Indeed more than $60 \%$ of nursing students had poor or mediocre scores.

Like the doctors, the health promoters tended to underestimate their knowledge. Although $63 \%$ of them rated their knowledge as excellent or good and $20 \%$ rated their knowledge as poor, $69 \%$ achieved excellent or good scores and only $8 \%$ achieved poor scores. However, owing to the small sample size ( $n$ 13) this may not be a representative reflection of their knowledge and the results should be interpreted with caution.

\section{Comparative mean knowledge scores}

Permanently employed doctors had the highest overall mean knowledge score (70 (SD 10) \%), followed by community service doctors (67 (SD 10) \%) and medical students (66 (SD 9) \%). Health promoters followed closely with an overall mean score of 66 (SD 15) \%. Professional nurses had a mean score of 60 (SD 10) \%, followed by nursing students (55 (SD 12) \%), enrolled nurses (54 SD 12) $\%$ ) and enrolled nursing assistants (49 (SD 12) \%; Table 2).

In each of the test sections the doctors had the highest mean scores, followed closely by the community service doctors and the health promoters. Nursing staff had mediocre scores across most categories, with enrolled nursing assistants attaining the lowest mean scores. As far as knowledge on dietary modification was concerned, both health professionals and students achieved the highest mean knowledge scores for the section on diet and hypertension. Except for the enrolled nursing assistants, all participants achieved good mean scores on the physical activity section. However, the section on weight loss was answered poorly by all categories of nursing staff and nursing students.

Despite the mean scores remaining more or less in the same region, the range of scores in most sections of the test was large, especially for the nursing staff. For example, although the mean physical activity scores for professional nurses, enrolled nurses and enrolled nursing assistants were 74 (sD 17) \%, 70 (sD 21) \% and 57 (sD 23) \%, respectively, the scores ranged between 0 and $100 \%$ across all three categories of nursing staff.

\section{Identified problem areas}

Questions that were poorly answered, where only 12-30\% of participants answered correctly, reflected areas of lifestyle modification that require further education and training. Some of these questions are illustrated in Table 3.

\section{Messages being promoted}

Table 4 presents some of the questions that were answered correctly by the majority of participants, thereby reflecting the messages that are currently being promoted. More than $90 \%$ of health professionals had the correct knowledge regarding some of the most important messages for patients with CDL.

\section{Practices}

\section{Self-reported bealth}

As seen in Fig. 1, 11\% of participants reported that they smoked, $54 \%$ that they participate in exercise regularly to maintain their fitness levels, $26 \%$ that they are overweight and $62 \%$ that they follow a healthy diet. Regression analysis of self-reported health demonstrated that health professionals and students who indicated that they followed a healthy diet were significantly $(P=0 \cdot 0012$ and

Table 2 Comparative mean knowledge test scores of respondents: public-sector primary-care health professionals and final-year students participating in the survey, Cape Town, South Africa

Test score per section (\%)

\begin{tabular}{|c|c|c|c|c|c|c|c|c|c|c|c|c|c|c|}
\hline \multirow[b]{3}{*}{ Professional group $(n)$} & \\
\hline & \multicolumn{2}{|c|}{ Diet and CHD } & \multicolumn{2}{|c|}{ Diet and HPT } & \multicolumn{2}{|c|}{ Diet and diabetes } & \multicolumn{2}{|c|}{ Diet and CDL } & \multicolumn{2}{|c|}{ Physical activity } & \multicolumn{2}{|c|}{ Weight loss } & \multirow{2}{*}{\multicolumn{2}{|c|}{$\frac{\text { Overall }}{\text { Mean SD }}$}} \\
\hline & Mean & SD & Mean & SD & Mean & SD & Mean & SD & Mean & SD & Mean & SD & & \\
\hline Doctors (49) & 64 & 17 & 79 & 14 & 68 & 13 & 68 & 18 & 81 & 13 & 71 & 13 & 70 & 10 \\
\hline Community service doctors (12) & 58 & 16 & 82 & 13 & 63 & 14 & 60 & 23 & 78 & 11 & 71 & 10 & 67 & 10 \\
\hline Medical students (181) & 60 & 13 & 74 & 14 & 60 & 13 & 62 & 22 & 78 & 18 & 71 & 15 & 66 & 9 \\
\hline Health promoters (13) & 61 & 21 & 77 & 19 & 64 & 19 & 63 & 23 & 77 & 19 & 59 & 23 & 66 & 15 \\
\hline Professional nurses (81) & 50 & 16 & 74 & 16 & 60 & 12 & 62 & 19 & 74 & 17 & 47 & 15 & 60 & 10 \\
\hline Nursing students (179) & 46 & 16 & 63 & 17 & 54 & 15 & 53 & 22 & 72 & 21 & 48 & 18 & 55 & 12 \\
\hline Enrolled nurses $(30)$ & 41 & 15 & 60 & 21 & 60 & 16 & 59 & 20 & 70 & 21 & 41 & 14 & 54 & 12 \\
\hline Nursing assistants (38) & 38 & 14 & 56 & 21 & 53 & 13 & 56 & 19 & 57 & 23 & 41 & 16 & 49 & 12 \\
\hline
\end{tabular}

HPT, hypertension; CDL, chronic diseases of lifestyle.

Professional nurse: a graduate trained nurse who has passed a state registration examination and has been licensed to practise.

Enrolled nurse: carries out nursing duties under the supervision of a professional nurse.

Nursing assistant: carries out nursing duties under the supervision of a professional nurse or an enrolled nurse.

Health promoters: health professionals specialising in health promotion and lifestyle modification. 
Table 3 Top ten questions answered incorrectly by the study participants: public-sector primary-care health professionals and final-year students participating in the survey, Cape Town, South Africa

\begin{tabular}{rcl}
\hline No. & \% Respondents & \multicolumn{1}{c}{ Question } \\
\hline 1 & 88 & Consumption of sugar in a diabetic diet \\
2 & 88 & Advice regarding alcohol consumption \\
3 & 85 & Cholesterol content of margarine \\
4 & 82 & Health benefits of brown sugar compared with white sugar \\
5 & 78 & Claim that apple cider vinegar promotes weight loss \\
6 & 76 & Classification of BMl \\
7 & 72 & Consumption of fruit juice in a diabetic patient's diet \\
8 & 71 & Cholesterol content of avocado pear \\
9 & 71 & Consumption of amasi (sour milk) in a diabetic diet \\
10 & 70 & Oral agents and meal patterns \\
\hline
\end{tabular}

Table 4 Top ten messages being promoted (questions correctly answered): public-sector primary-care health professionals and final-year students participating in the survey, Cape Town, South Africa

\begin{tabular}{rcl}
\hline No. & $\%$ Respondents & \multicolumn{1}{c}{ Question } \\
\hline 1 & 95 & Walking and gardening increases physical activity levels \\
2 & 94 & $\begin{array}{l}\text { Adding salt to food at the table should be avoided } \\
\text { Consumption of sugar in tea/coffee should be avoided }\end{array}$ \\
3 & 93 & Consumption of fruit is allowed in a diabetic patient's diet \\
4 & 92 & $\begin{array}{l}\text { Saturated fats such as those found in full cream milk, butter, meat and chicken skin increase } \\
\text { blood cholesterol levels }\end{array}$ \\
5 & 92 & Lentils and dried beans should be allowed in a CHD patient's diet \\
6 & 91 & A low-fat diet is beneficial in all chronic diseases of lifestyle \\
7 & 91 & Herbs can be used to flavour foods instead of salt \\
8 & 91 & Patients should be advised to perform 30 min of exercise daily \\
9 & 90 & Lentils should be allowed in a diabetic patient's diet
\end{tabular}

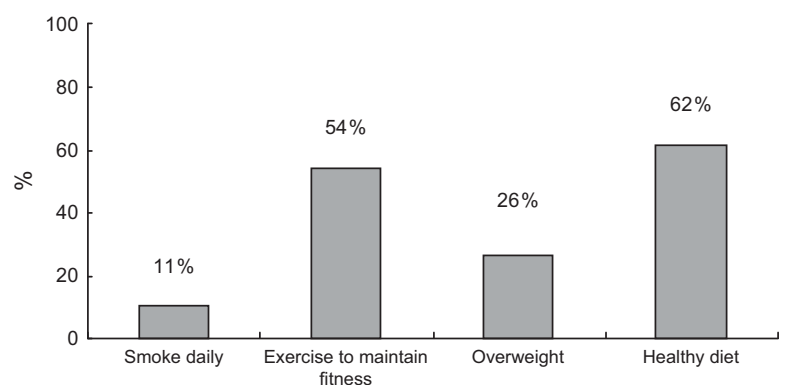

Fig. 1 Self-reported practices of survey respondents: publicsector primary-care health professionals and final-year students, Cape Town, South Africa

$P=0 \cdot 0064$, respectively) more likely to achieve higher scores on the knowledge test than those who did not.

\section{Main sources of information}

Figure 2 illustrates that the majority of participants identified the mass media as their main source of information on smoking and physical activity, while more than a third identified textbooks as the main source of information on diet.

\section{Confidence in counselling}

The majority of health professionals and students indicated that they were quite confident $(56 \%$ and $55 \%$, respectively) or very confident $(24 \%$ and $20 \%$, respectively) in providing counselling on lifestyle modification.

\section{Barriers preventing counselling}

Lack of time, lack of patient compliance and language barriers were identified by more than $70 \%$ of health professionals and less than $52 \%$ of students as barriers that $\mathrm{do} /$ would prevent them from providing counselling on lifestyle modification (Fig. 3). Very few participants cited a lack of knowledge and inadequate counselling skills as barriers to counselling.

\section{Practices implemented on initial patient visit}

Although most health professionals often measure weight, take a dietary history and enquire about both smoking and physical activity habits (Fig. 4), less than half of the health professionals measure height and calculate BMI.

Access to and consultation with experts in lifestyle modification

The majority of health professionals indicated that they do not have access to or consult with experts in physical activity (90\% and $88 \%$, respectively) or smoking cessation ( $82 \%$ and $84 \%$, respectively). Furthermore, only $39 \%$ of health professionals indicated that they often have access to dietitians, compared with $26 \%$ who indicated that they often consult dietitian.

Knowledge and practices regarding smoking cessation Most health professionals (84\%) and students (71\%) indicated that they $\mathrm{do} /$ would routinely advise patients to stop smoking. However, while more than $90 \%$ of students 


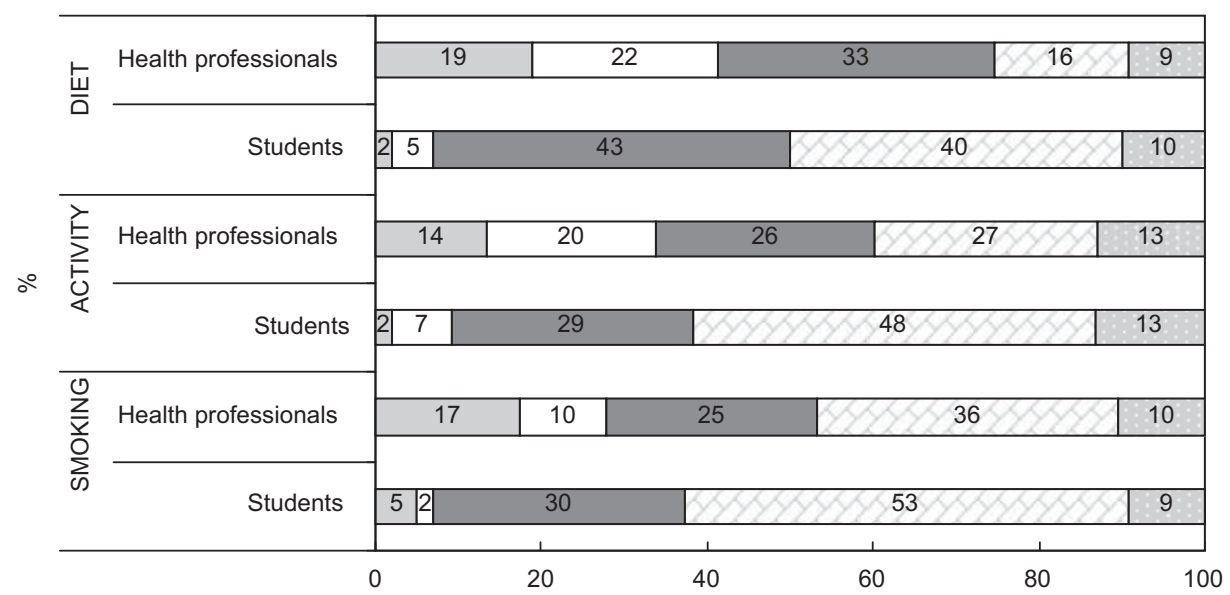

Fig. 2 Main sources of information $(\square$, journals; $\square$, workshops; $\square$, textbooks; $\square$, mass media; $\square$, other) as provided by survey respondents: public-sector primary-care health professionals and final-year students, Cape Town, South Africa

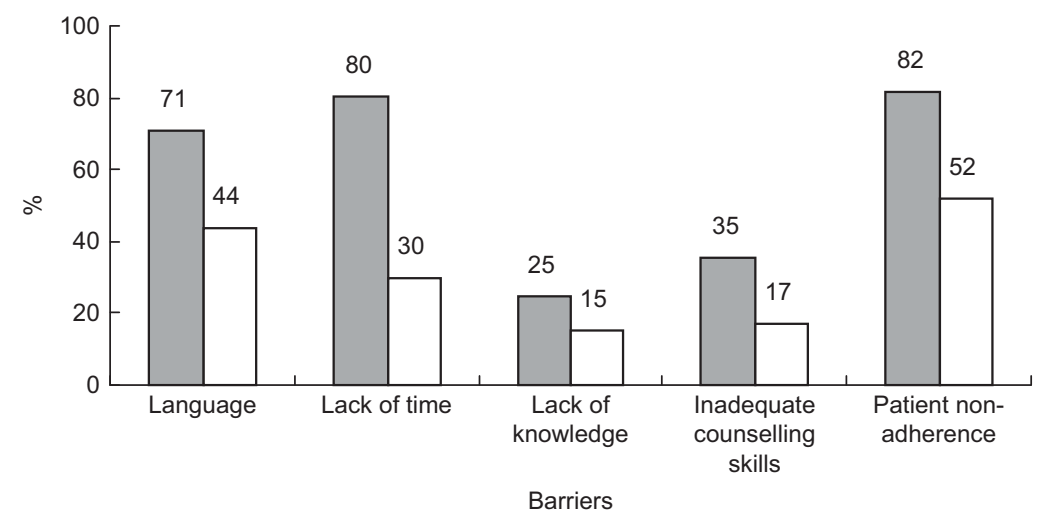

Fig. 3 Barriers preventing lifestyle modification counselling on diet, physical activity and smoking cessation as provided by survey respondents ( $\square$, health professionals; $\square$, students): public-sector primary-care health professionals and final-year students, Cape Town, South Africa

indicated that they would enquire about smoking habits in all patients, health professionals were more likely to restrict their enquiries to CDL patients, CHD patients, pregnant women and adult males, and were thus less likely to make enquiries from females and adolescents.

The most common methods of smoking cessation recommended by health professionals and students were tapering off ( $61 \%$ and $80 \%$, respectively), counselling by health professionals ( $49 \%$ and $90 \%$, respectively) and nicotine replacement therapy ( $33 \%$ and $88 \%$, respectively).

\section{Discussion and recommendations}

Lifestyle modification is not only one of the cornerstones of the management of people with CDL, it is of fundamental importance in primary prevention. Yet the vast majority of South Africans do not have access to dietitians, biokineticists and smoking cessation counsellors who can provide detailed input on lifestyle modification. In the public health sector, doctors, nurses and health promoters are relied upon to dispense this information.

It is encouraging to note, from individual interviews conducted $^{(68)}$, that health professionals have a positive attitude to lifestyle modification. For example, they identified patient education as one of their major roles and commented on the positive role of lifestyle modification in preventing and managing CDL. They also expressed their desire to care for their community and their sense of achievement and excitement when thanked by patients for their advice, which motivated them to provide counselling. Interestingly, they ranked diabetes and hypertension above other common chronic conditions such as HIV and tuberculosis in terms of providing health education, as diabetic and hypertensive patients comprised the largest proportion of their patient load.

However the current study clearly shows that there is an undeniable misalignment of health professionals' actual and perceived lifestyle modification knowledge. Simply put, they say they are knowledgeable but the 


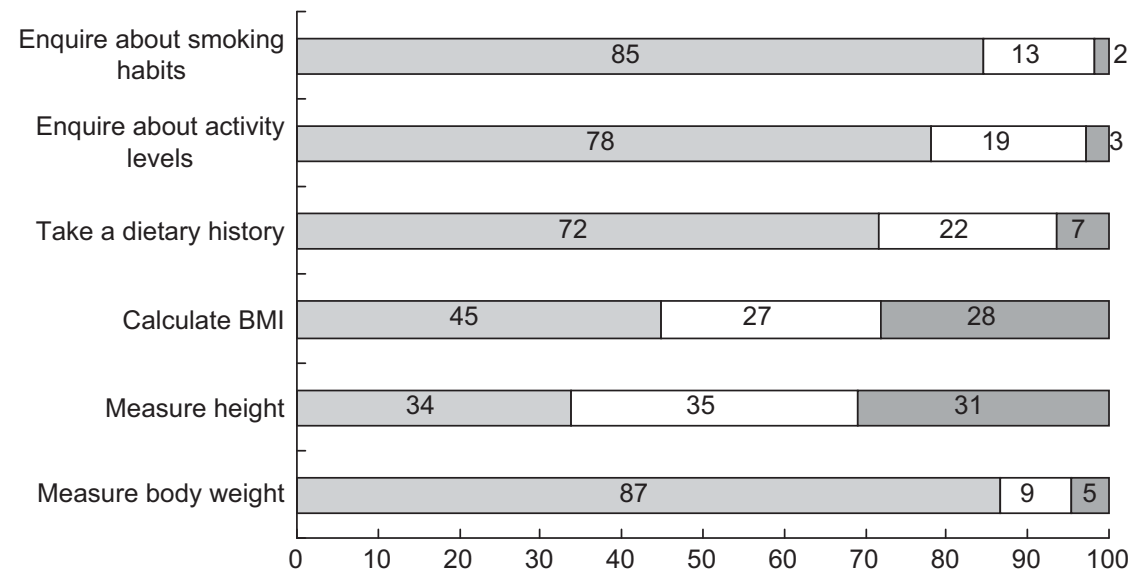

Fig. 4 Practices by public-sector primary-care health professionals at a first consultation with a patient with a chronic disease ( , often; - , sometimes;, , seldom), Cape Town, South Africa

majority of them are not. The range of knowledge demonstrated in the study indicates that misinformation and misconceptions regarding lifestyle modification are rife among health professionals. These results are particularly disturbing since the study tested health professionals' applied knowledge of lifestyle modification, directly providing an indication of the information that they dispense to their CDL patients.

These perceptions lead to misplaced complacency among health professionals and explain why they do not view lack of knowledge as a barrier to counselling. Even more disturbing is the fact that they are confident in providing lifestyle modification counselling to patients, which begs the question: are patients really benefiting from the current counselling sessions?

Although doctors and medical students appear to have reasonable knowledge on the topic, they seldom have the opportunity to impart their knowledge to their patients. This is attributed to the structure of the primary health services for CDL patients, whereby patients are regularly (usually once a month) seen by nurses and are referred to doctors only twice a year for a consultation that lasts approximately 5-7 min during which everything from examination to re-issuing medical prescriptions and counselling has to take place ${ }^{(68)}$. Many doctors also experience language barriers which further hinder the provision of counselling. As a result the nursing staff, who have displayed alarmingly poor knowledge, are the main providers of health promotion and education in PHC facilities.

Yet patients (interviewed in another aspect of the current study) have clearly indicated that they prefer to receive information via individual counselling sessions with a doctor or nurse ${ }^{(68)}$. In the PHC setting this is clearly not sustainable due to large patient loads; even if it were, improving the knowledge of the nurses requires urgent attention.

It is apparent that the way in which education should be delivered at PHC facilities needs to be reviewed.
Health promoters and nutrition advisors at these facilities are specifically trained and employed to provide health education and counselling to patients on a variety of topics including lifestyle modification. Since health promoters' knowledge parallels that of doctors and exceeds that of nursing staff, this group provides an alternative avenue through which patients can be supported to adopt healthier lifestyles. While very few patients reported that they would prefer to receive information from these health promoters or nutrition advisors, this may be attributed to patients placing more value on information provided by nurses and doctors as they are perceived to have a higher status than health promoters and nutrition advisors. On the other hand, it reflects patients' lack of exposure to them as they are currently available at only a few PHC facilities. It is necessary to promote, advocate and appreciate the value and use of PHC health promoters and nutrition advisors among patients and other health professionals at PHC level, to facilitate referrals and endorse the services that they provide. Concurrently, more posts for this group should be created to ensure that their services are available at all PHC facilities and to enable proper utilisation of staff.

The poor knowledge scores achieved, especially among the nurses, is linked to the observation that they receive the majority of their lifestyle modification information via the mass media. Mass media campaigns have been shown to be effective in improving the lifestyle modification knowledge of the general public ${ }^{(69-79)}$ and thus this avenue of health promotion should be utilised effectively for the population as a whole. Health professionals, however, require more exposure and training in lifestyle modification. There is a need to review their training in this regard as well as to standardise the information that health professionals, students and patients are exposed to. The manner in which this training should occur needs careful thought as it needs to be 
addressed at both undergraduate and practising health professional level.

Today there is a lot of emphasis on prevention, but to what extent are factors of lifestyle modification incorporated into training? Currently there is a large focus on pharmacotherapy, but to what extent do training institutions go beyond the rhetoric of a healthy lifestyle? At present medical students are exposed to lifestyle modification as part of their curriculum during periods within their fourth, fifth and sixth years, while nursing students gain exposure during their first year. This exposure implicitly communicates lifestyle education as part of patient care but no explicit dedicated lectures or seminars on the topic currently exist in their curricula. The need for the development of suitable training modules in lifestyle modification during undergraduate training should be brought to the attention of the relevant educational institutions. Altering the student curriculum has been a recommendation commonly cited in the literature ${ }^{(42,47,48,61,62,80,81)}$; however, this is a challenge as health professional training curricula are very full and thus the viability of this recommendation remains to be tested. The curriculum should be restructured to include training on actual lifestyle modification modules, which are not solely restricted to theory but include practical workshops on how to apply theoretical knowledge.

Health professionals working at PHC facilities can be trained by providing continuous education in lifestyle modification. This could take the form of a postgraduate diploma for nurses in CDL management at tertiary institutions. In order for such a programme to be attractive some form of incentive such as increased remuneration or even sponsorship may be required. There are precedents within the HIV realm where training courses such as the Diploma in HIV Management, offered by the College of Family Physicians of South Africa ${ }^{(82)}$, contributes towards career development and career paths. Improving lifestyle modification education at continuing medical education courses has also been recommended in the literature ${ }^{(43,44)}$. Thus attendance at lifestyle modification and chronic disease management workshops could form an essential component of continuing education for both medical and nursing professionals.

Due to the current lack of medical and nursing staff at PHC facilities, a more viable recommendation may be to provide in-service training to staff. There is currently an existing in-service training programme (PALSA PLUS) which has been effective in simultaneously improving the quality of care for chronic (asthma) and infectious diseases (tuberculosis) ${ }^{(83)}$. Staff exposed to this programme have requested its expansion to address other chronic diseases, specifically diabetes, hypertension and CVD.

It is important to bear in mind that the present study was conducted in the best-resourced province in South Africa and that these findings probably provide the bestcase scenario. Due to a lack of resources, other provinces in South Africa are likely to be worse-off. In order to address this and give due diligence to the rhetoric of a healthy lifestyle, the first point of call would be to address the complacency regarding this topic by aligning health professionals' perceived knowledge with their actual knowledge and then to embark upon the training that they both receive and require.

\section{Acknowledgements}

Source of funding: This research was funded by the South African Medical Research Council and the Department of Science and Technology. Conflict of interest: None. Authors' contributions: W.P. was the principal researcher and author. N.P.S. and N.S.L. were co-authors and COinvestigators. C.J.L. conducted the statistical analyses. Acknowledgements: We thank the management, staff and patients of the PHC facilities, as well as the course convenors and students at the four tertiary institutions, for their participation in the study.

\section{References}

1. Bourne LT, Lambert EV \& Steyn K (2002) Where does the black population of South Africa stand on the nutrition transition? Public Health Nutr 5, 157-162.

2. Bradshaw D, Schneider M, Norman R et al. (2006) Mortality patterns of chronic diseases of lifestyle in South Africa. In Chronic Diseases of Lifestyle 1995-2005, pp. 9-22 [K Steyn, $\mathrm{J}$ Fourie and $\mathrm{N}$ Temple, editors]. Cape Town: Medical Research Council.

3. Wikipedia (2008) Health care systems. http://en.wikipedia.org/wiki/Health_care_system (accessed August 2008).

4. Knowler WC, Barret-Connor E, Fowler SE et al. (2002) Reduction on the incidence of type 2 diabetes with lifestyle intervention or metformin. N Engl J Med 346, 393-401.

5. Herman WH, Hoerger TJ, Brandle M et al. (2005) The costeffectiveness of lifestyle modification or metformin in preventing type 2 diabetes in adults with impaired glucose tolerance. Ann Intern Med 142, 323-332.

6. Ockene IS, Hebert JR, Ockene JK et al. (1996) Effect of training and a structured office practice on physiciandelivered nutrition counseling: the Worcester-Area Trial for Counseling in Hyperlipidemia (WATCH). Am J Prev Med 12, 252-258.

7. Ockene IS, Herbert JR, Ockene JK et al. (1999) Effect of physician-delivered nutrition counseling training and an office support program on fat intake, weight and serum lipid measurements in a hyperlipidemic population: the Worcester-Area Trial for Counseling in Hyperlipidemia (WATCH). Arch Intern Med 159, 725-731.

8. Herbert JR, Ebbeling CB, Ockene IS et al. (1999) A dietitiandelivered group nutrition program leads to reductions in dietary fat, serum cholesterol, and body weight: the Worcester-Area Trial for Counselling in Hyperlipidemia (WATCH). J Am Diet Assoc 99, 544-552.

9. Pritchard DA, Hyndman J \& Taba F (1999) Nutritional counselling in general practice: a cost-effective analysis. J Epidemiol Community Health 53, 311-316.

10. Steptoe A, Doherty S, Rink E et al. (1999) Behavioural counselling in general practice for the promotion of healthy behaviour among adults at increased risk of coronary heart disease: randomised trial. BMJ 319, 943-947. 
11. Steptoe A, Perkins-Porras L, McKay C et al. (2003) Behavioural counselling to increase consumption of fruit and vegetables in low income adults: randomized trial. $B M J$ 326, 855 .

12. Steptoe A, Kerry S, Rink E et al. (2001) The impact of behavioral counseling on stage of change in fat intake, physical activity, and cigarette smoking in adults at increased risk of coronary heart disease. Am J Public Health 91, 265-269.

13. Beresford SA, Curry SJ, Kristal AR et al. (1997) A dietary intervention in primary care practice: the Eating Patterns Study. Am J Public Health 87, 610-616.

14. Lazovich D, Curry SJ, Beresford SA et al. (2000) Implementing a dietary intervention in primary care practice: a process evaluation. Am J Health Promot 15, 118-125.

15. O'Halloran P, Lazovich D, Patterson RE et al. (2001) Effect of health lifestyle pattern on dietary change. Am J Health Promot 16, 27-33.

16. John JH, Ziebland S, Yudkin PL et al. (2002) Effects of fruit and vegetable consumption on plasma antioxidant concentrations and blood pressure: a randomised controlled trial. Lancet 359, 1969-1974.

17. John JH, Yudkin PL, Neil HAW et al. (2003) Does stage of change predict outcome in a primary-care intervention to encourage an increase in fruit and vegetable consumption? Health Educ Res 18, 429-438.

18. John JH \& Ziebland S (2004) Reported barriers to eating more fruit and vegetables before and after participation in a randomised controlled trial: a qualitative study. Health Educ Res 19, 165-174.

19. Bowen DB, Ehret C, Pedersen M et al. (2002) Results of an adjunct dietary intervention program in the Women's Health Initiative. J Am Diet Assoc 102, 1631-1637.

20. Patterson RE, Kristal A, Rodabough R et al. (2003) Changes in food sources of dietary fat in response to an intensive low fat dietary intervention: early results from the Women's Health Initiative. J Am Diet Assoc 103, 454-460.

21. Kearney MH, Rosal MC, Ockene JK et al. (2002) Influences on older women's adherence to a low fat diet in the Women's Health Initiative. Psychosom Med 64, 450-457.

22. Hopkins S, Burrows E, Bowen DJ et al. (2001) Differences in eating pattern labels between maintainers and nonmaintainers in the Women's Health Initiative. J Nutr Educ Behav 33, 278-283.

23. Langer RD, White E, Lewis CE et al. (2003) The Women's Health Initiative Observational Study: baseline characteristics of participants and reliability of baseline measures. Ann Epidemiol 13, 9 Suppl., S107-S121.

24. Ritenbaugh C, Patterson RE, Chlebowski RT et al. (2003) The Women's Health Initiative dietary modification trial: overview and baseline characteristics of participants. Ann Epidemiol 13, 9 Suppl., S87-S97.

25. Anderson GL, Manson J, Wallace R et al. (2003) Implementation of the Women's Health Initiative study design. Ann Epidemiol 13, 9 Suppl., S5-S17.

26. Patterson RE (2004) Dietary adherence in the Women's Health Initiative dietary modification trial. J Am Diet Assoc 104, 654-658.

27. Beresford SA, Johnson KC, Ritenbaugh C et al. (2006) Lowfat dietary pattern and risk of colorectal cancer: the Women's Health Initiative Randomized Controlled Dietary Modification Trial. JAMA 295, 643-654.

28. Prentice RL, Caan B, Chlebowski RT et al. (2006) Low-fat dietary pattern and risk of invasive breast cancer: the Women's Health Initiative Randomized Controlled Dietary Modification Trial. JAMA 295, 629-642.

29. Howard BV, Van Horn L, Hsia J et al. (2006) Low-fat dietary pattern and risk of cardiovascular disease: the Women's Health Initiative Randomized Controlled Dietary Modification Trial. JAMA 295, 655-666.
30. Howard BV, Manson JE, Stefanick ML et al. (2006) Low-fat dietary pattern and weight change over 7 years: the Women's Health Initiative Randomised Controlled Dietary Modification Trial. JAMA 295, 39-49.

31. Huxley RR, Lean M, Crozier A et al. (2004) Effect of dietary advice to increase fruit and vegetable consumption on plasma flavonol concentrations: results from a randomised controlled intervention trial. $J$ Epidemiol Community Health 58, 288-299.

32. Ramachandran A, Snehalatha C, Mary S et al. (2006) The Indian Diabetes Prevention Programme shows that lifestyle modification and metformin prevent type 2 diabetes in Asian Indian subjects with impaired glucose tolerance (IDPP-1). Diabetologia 49, 289-297.

33. Mohan V, Shanthirani CS, Deepa M et al. (2006) Community empowerment - a successful model for prevention of non-communicable diseases in India - the Chennai Urban Population study (CUPS-17). J Assoc Physicians India 54, 858-862.

34. Staten LK, Scheu LL, Bronson D et al. (2005) Pasos Adelante: the effectiveness of a community-based chronic disease prevention program. Prev Chronic Dis 2, A18.

35. Qureshi NN, Hatcher J, Chaturvedi N et al. (2007) Effect of general practitioner education on adherence to antihypertensive drugs: cluster randomized control trial. BMJ 335, 1030.

36. Goldhaber-Fiebert JD, Goldhaber-Fiebert SN, Tristan ML et al. (2003) Randomized controlled community-based nutrition and exercise intervention improves glycemia and cardiovascular risk factors in type 2 diabetic patients in rural Costa Rica. Diabetes Care 26, 24-29.

37. Oosthuizen H, Riedijk R, Nonner J et al. (2002) An educational intervention to improve the quality of care of diabetic patients. S Afr Med J 92, 457-464.

38. Reddy M, Boschmans SA \& McCartney J (2004) Design of a structured diabetic record card based on the national diabetes guidelines. JEMDSA 9, 36 .

39. Reddy M, Boschmans SA \& McCartney J (2004) Impact of a structured medical record card on glycaemic and blood pressure control among diabetic patients at a primary health care clinic. JEMDSA 9, 36.

40. Fernando DJ (1993) Knowledge about diabetes and metabolic control in diabetic patients. Ceylon Med J 38, 18-21.

41. Van Weel C (1997) Morbidity in family medicine: the potential for individual nutrition counseling, an analysis from the Nijmegen Continuous Morbidity Registration. Am J Clin Nutr 65, 6 Suppl., 1928S-1932S.

42. Egede LE \& Zheng D (2002) Modifiable cardiovascular risk factors in adults with diabetes: prevalence and missed opportunities for physician counseling. Arch Intern Med 162, 427-433.

43. Moore H, Adamson AJ, Gill T et al. (2000) Nutrition and the health care agenda. Fam Pract 17, 197-202.

44. Hiddink GJ, Hausvast JG, van Woerkum CM et al. (1997) Consumer's expectations about nutrition guidance: the importance of primary care physicians. Am J Clin Nutr $\mathbf{6 5}$, 6 Suppl., 1974S-1979S.

45. Kolasa KM (2001) 'Images' of nutrition in medical education and primary care. Am J Clin Nutr 73, 1006.

46. van Dillen SME, Hiddink GJ, Koelen MA et al. (2003) Understanding nutrition communication between health professionals and consumers: development of a model for nutrition awareness based on qualitative consumer research. Am J Clin Nutr 77, 4 Suppl., 1065S-1072S.

47. Serra-Majem LL, Calvo JR, Male ML et al. (1999) Population attitudes towards changing dietary habits and reliance on general practitioners in Spain. Eur J Clin Nutr 53, Suppl. 2, S58-S61.

48. Buttriss JL (1997) Food and nutrition: attitudes, beliefs and knowledge in the United Kingdom. Am J Clin Nutr $\mathbf{6 5}$, 6 Suppl., 1985S-1995S. 
49. Truswell AS (2000) Family physicians and patients: is effective nutrition interaction possible? Am J Clin Nutr $\mathbf{7 1}$, 6-12.

50. Westa R, McNeill A \& Rawe M (2000) Smoking cessation guidelines for health professionals: an update. Thorax $\mathbf{5 5}$, 987-999.

51. Thun M \& Glynn TJ (2000) Improving the treatment of tobacco dependence. BMJ 321, 311-312.

52. Harris SS, Caspersen CJ, DeFriese GH et al. (1989) Physical activity counselling for healthy adults as a primary preventive intervention in the clinical setting. Report for the US Preventive Services Task Force. JAMA 261, 3588-3598.

53. Allen SS, Harris IB, Kofron PM et al. (1992) A comparison of knowledge of medical students and practicing primary care physicians about cardiovascular risk assessment and intervention. Prev Med 21, 436-448.

54. Stead LF, Bergson G \& Lancaster T (2008) Physician advice for smoking cessation. Cochrane Database Syst Rev issue 2, CD000165.

55. Peiss B, Kurleto B \& Rubenfire M (1995) Physicians and nurses can be effective educators in coronary risk reduction. Gen Intern Med 10, 77-81.

56. Kreuter MW, Chheda SG \& Bull FC (2000) How does physician advice influence patient behaviour? Evidence for a priming effect. Arch Fam Med 9, 426-433.

57. Egede LE (2003) Lifestyle modification to improve blood pressure control in individuals with diabetes. Is physician advice effective? Diabetes Care 26, 602-607.

58. Moore H \& Adamson AJ (2002) Nutrition interventions by primary care staff: a survey of involvement, knowledge and attitude. Public Health Nutr 5, 531-536.

59. Temple NJ (1999) Survey of nutrition knowledge of Canadian physicians. J Am Coll Nutr 18, 26-29.

60. Mlodinow SG \& Barrett-Connor E (1989) Physicians' and medical students' knowledge of nutrition. Acad Med 64, 105-106.

61. Podell RN, Gary LR \& Keller K (1975) A profile of clinical nutrition knowledge among physicians and medical students. J Med Educ 50, 888-892.

62. Vengetasamy $\mathrm{T}(2002)$ The nutritional knowledge, attitudes and practices of general practitioners in the greater Cape Town area. MSc Thesis, University of Cape Town.

63. Hankey C, Eley S, Leslie W et al. (2004) Eating habits, beliefs, attitudes and knowledge among health professionals regarding the links between obesity, nutrition and health. Public Health Nutr 7, 337-343.

64. Wikipedia (2009) List of African countries by GDP (PPP). http://en.wikipedia.org/wiki/List_of_African_countries_by_ GDP (accessed August 2009).

65. Reagon G, Irlam J \& Levin J (2004) The National Primary Health Facilities Survey 2003. Durban: Health Systems Trust and Department of Health.

66. Myers J \& Naledi T (2007) Western Cape Burden of Disease Reduction Project. vol. 1: Overview of the Report. Cape Town: Western Cape Department of Health.

67. Talip W, Steyn NP, Visser ME et al. (2003) Development and validation of a knowledge test for health professionals regarding lifestyle modification. Nutrition 19, 760-766.
68. Parker W (2008) Lifestyle modification education in chronic diseases of lifestyle: insight into counselling provided by health professionals at primary health care facilities in the Western Cape, South Africa. PhD Thesis, University of Cape Town.

69. Ezenwaka CE \& Offiah NV (2003) Patients' health education and diabetes control in a developing country. Acta Diabetol 40, 173-175.

70. Reger B, Wootan MG \& Booth-Butterfield S (1999) Using mass media to promote healthy eating: a community-based demonstration project. Prev Med 29, 414-421.

71. Reger B, Wootan MG, Booth-Butterfield S et al. (1998) $1 \%$ or less: a community-based nutrition campaign. Public Health Rep 113, 410-419.

72. Braeckman L, De Bacquer D, Maes L et al. (1999) Effects of a low-intensity worksite-based nutrition intervention. Occup Med (Lond) 49, 549-555.

73. Pegus C, Bazzarre TL, Brown JS et al. (2002) Effect of the Heart At Work program on awareness of risk factors, selfefficacy, and health behaviors. J Occup Environ Med $\mathbf{4 4}$, 228-236.

74. Foerster SB, Kizer KW, DiSogra LK et al. (1995) California's ' 5 a day - for better health' campaign: an innovative population-based effort to effect large-scale dietary change. Am J Prev Med 11, 124-131.

75. van Wechem SN, Brug J, van Assema P et al. (1998) Fat Watch: a nationwide campaign in The Netherlands to reduce fat intake - effect evaluation. Nutr Health 12, 119-130.

76. Dixon H, Borland R, Segan C et al. (1998) Public reaction to Victoria's '2 Fruit 'n' 5 Veg Every Day' campaign and reported consumption of fruit and vegetables. Prev Med 27, 572-582.

77. Curran S, Gittelsohn J, Anliker J et al. (2005) Process evaluation of a store-based environmental obesity intervention on two American Indian Reservations. Health Educ Res 20, 719-729.

78. Ritenbaugh C, Teufel-Shone NI, Aickin MG et al. (2003) A lifestyle intervention improves plasma insulin levels among Native American high school youth. Prev Med 36, 309-319.

79. Kelder SH, Perry CL, Lytle LA et al. (1995) Community-wide youth nutrition education: long-term outcomes of the Minnesota Heart Health Program. Health Educ Res 10, 119-131.

80. Tsui JI, Dodson K \& Jacobson TA (2004) Cardiovascular disease prevention counseling in residency: resident and attending physician attitudes and practices. $J$ Natl Med Assoc 96, 1088-1091.

81. Shai I, Shahar D \& Fraser D (2001) Attitudes of physicians and medical students toward nutrition's place in patient care and education at Ben-Gurion University. Educ Health (Abingdon) 14, 405-415.

82. Colleges of Medicine of South Africa (2008) Diploma in HIV management of the College of family physicians of South Africa. http://www.collegemedsa.ac.za/view_exam.asp?Type $=$ Link\&ExamID $=59$ (accessed August 2008).

83. Fairall L, Zwarenstein M, Bateman E et al. (2005) Educational outreach to nurses improves tuberculosis case detection and primary care of respiratory illness: a pragmatic cluster randomized controlled trial. BMJ 331, 750-754. 